\title{
CONTROL DE LA PESTE EN LA LIBERTAD, PERÚ
}

\author{
[PLAGUE CONTROL IN LA LIBERTAD, PERU]
}

\author{
Paul E. Pachas 1,a,b, Leonardo Mendoza ${ }^{1, c}$, Dana González ${ }^{1, c}$ \\ Víctor Fernández ${ }^{2, d}$, Manuel Céspedes ${ }^{1, b, c}$
}

\section{RESEÑA HISTÓRICA}

La peste bubónica es una de las enfermedades más temidas por el hombre, ha ocasionado tres grandes pandemias; la primera, Ilamada la peste de Justianiano (541-542 AC); se inició en África y se expandió desde Egipto hasta el Mar Mediterráneo, ocasionó entre 40 a 100 millones de muertes. La segunda, Ilamada la peste negra (1347 a 1350); se originó en Asia Central y se expandió a Europa, ocasionó la muerte de cerca de 25 millones de personas, un tercio de la población de Europa. La tercera, se inició en China durante la primera mitad del siglo XIX y se diseminó por vía marítima desde Hong Kong a todo el mundo $(1,2)$ ocasionó la muerte de cerca de 12 millones de personas, principalmente en India.
Durante la epidemia de Hong Kong, en 1894, Alexander Yersin y Shibasaburo Kitasato describen, en forma independiente y con unos días de diferencia, el aislamiento del agente etiológico de la peste. Yersin describe la asociación entre las ratas y la peste, pero son Masanori Ogata y Paul Louis Simond quienes describen el rol de la pulga en la transmisión de la peste durante la epidemia en la India en $1897^{(3)}$.

Existen focos enzoóticos en todo el mundo, pero los casos en humanos en la actualidad ocurren principalmente en África ${ }^{(3)}$ en países como República Democrática del Congo, Madagascar, Mozambique, Tanzania, Kenya, Lesoto, Namibia, Senegal, Sudáfrica y Uganda (4). En el año 2003 se notificó a la OMS 2118 casos provenientes de nueve países ${ }^{(4)}$. La peste llegó a las Américas en

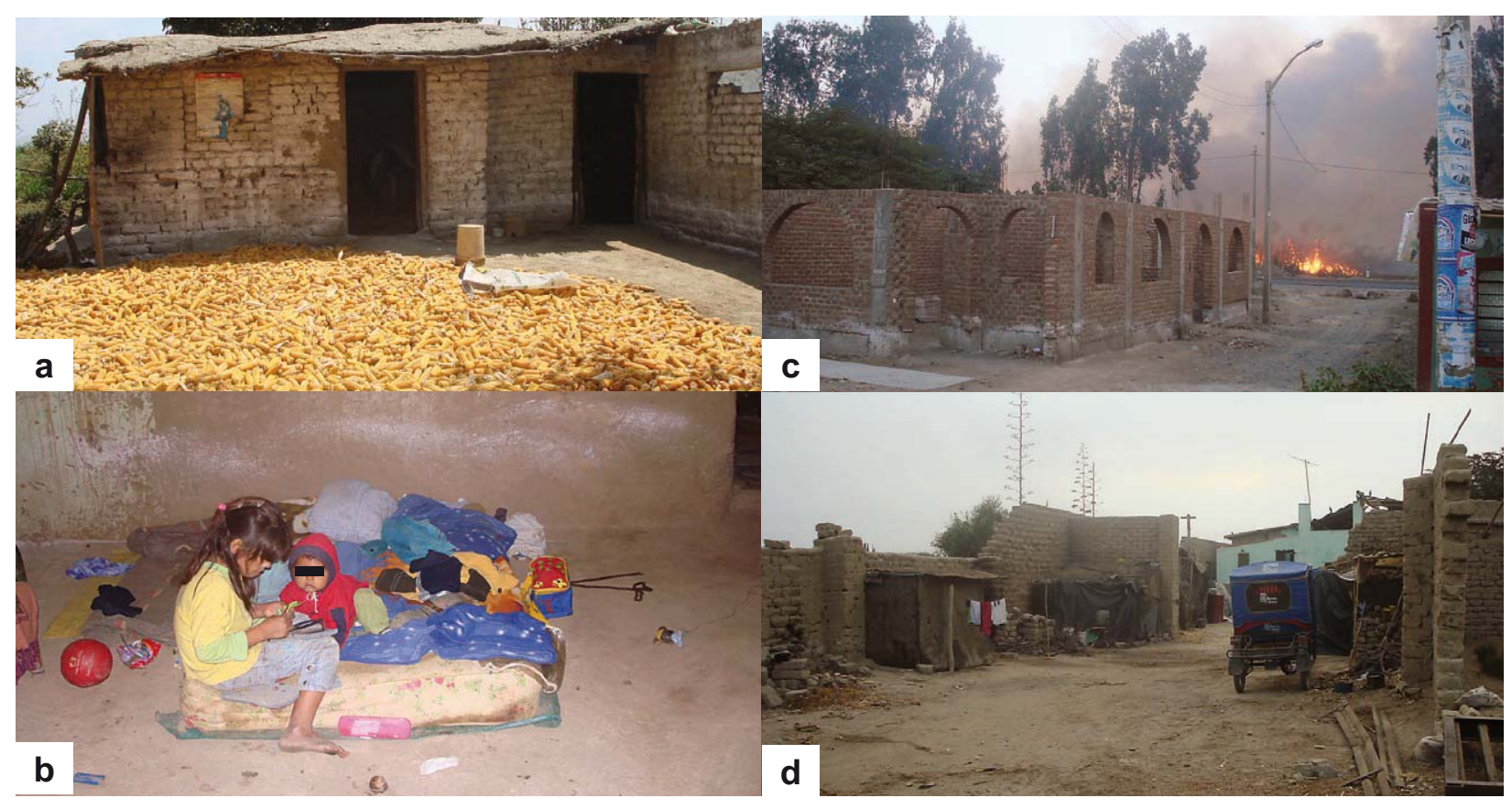

Figura 1. Se ha reportado múltiples factores de riesgo, que están siendo investigados: en estas imágenes se muestran algunos. (a) Almacenamiento de las cosechas alrededor o dentro de la casa; (b) dormir en colchones o tarimas colocados sobre el suelo; (c) quemar la caña de azúcar para cosecharla cerca a los poblados y; (d) habitar en viviendas rústicas hechas de plásticos y palos, lugares donde se alojan los inmigrantes ("golondrinos") de Cajamarca que trabajan en la cosecha de la caña de azúcar.

\footnotetext{
1 Centro Nacional de Salud Pública, Instituto Nacional de Salud. Lima, Perú.

2 Laboratorio Referencial Regional de La Libertad, Gerencia Regional de Salud, Gobierno Regional La Libertad. Trujillo, Perú.

a Médico epidemiólogo, ${ }^{b}$ Magíster (c) en salud pública; ${ }^{\mathrm{c}}$ Biólogo; ${ }^{\mathrm{d}}$ Médico infectólogo.
}

$$
\text { Recibido: 10-09-10 Aprobado: 15-09-10 }
$$



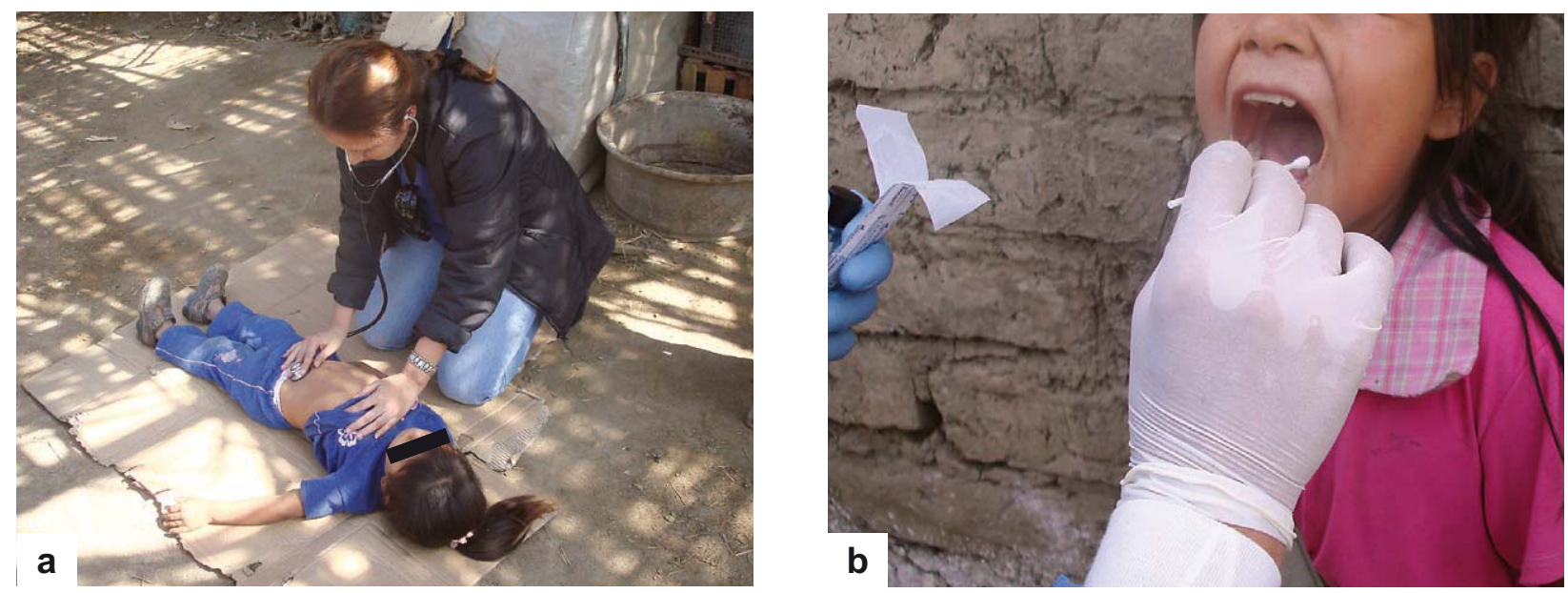

Figura 2. Como parte de los estudios de prevalencia de anticuerpos, la búsqueda activa de casos de peste y el estudio de factores de riesgo, se ha evaluado a personas febriles y casos sospechosos de peste. (a) Examen clínico realizado en la vivienda de los casos, (b) colecta de hisopado faríngeo para diagnóstico de Y. pestis con PCR.

1899 a Paraguay y en 1900 a San Francisco. Luego, se estableció en focos enzoóticos en Brasil, Perú, Bolivia, Ecuador y los Estados Unidos ${ }^{(4)}$.

\section{LA PESTE EN EL PERÚ}

Llegó al Perú en 1903 por los puertos del Callao y Pisco y se extendió rápidamente a otras ciudades de la costa. Entre los años 1912 y 1915 se expandió a las áreas rurales donde se mantiene en forma enzoótica, en un ciclo que incluye a roedores silvestre y sus pulgas. Se ha focalizado en los departamentos de Piura, Cajamarca, Lambayeque y La Libertad donde ocasionalmente se notifican brotes. Los brotes más grandes en los últimos 20 años ocurrieron en el año 1993 con 610 casos y en 1994 con 1128 casos. En los últimos diez años se han presentado brotes pequeños y aislados en las provincias de Jaén, San Ignacio, Chota y San Miguel en el departamento de Cajamarca.
En el año 2009 se presentó un brote de peste en el distrito de Casagrande, provincia de Ascope, departamento de La Libertad donde Se logró aislar Yersinia pestis de humanos y de una rata de la especie Rattus rattus. En abril de 2010 se presentó otro brote en el distrito de Chicama, ubicado a $32 \mathrm{~km}$ de la ciudad de Trujillo.

Lamentablemente, existen pocas investigaciones publicadas en revistas científicas indizadas y realizadas en el Perú. La búsqueda bibliográfica de los últimos 15 años, en la base de datos SciELO, solo recuperó cuatro estudios: dos sobre vectores y reservorios en Piura ${ }^{(5,6)}$, que reportaron a Pulex irritans, Tiamastus cavicola y Ctenocephalides canis como las principales especies de pulgas en las viviendas. Los principales roedores encontrados fueron Rattus rattus, Akodon spp, Mus musculus y Oryzomys spp. Un tercer estudio reportó la purificación de la fracción antigénica F1 de Yersinia pestis $^{(7)}$ y otro estudio sobre el impacto económico de la peste en Cajamarca ${ }^{(8)}$ reportó que para el año 1994,

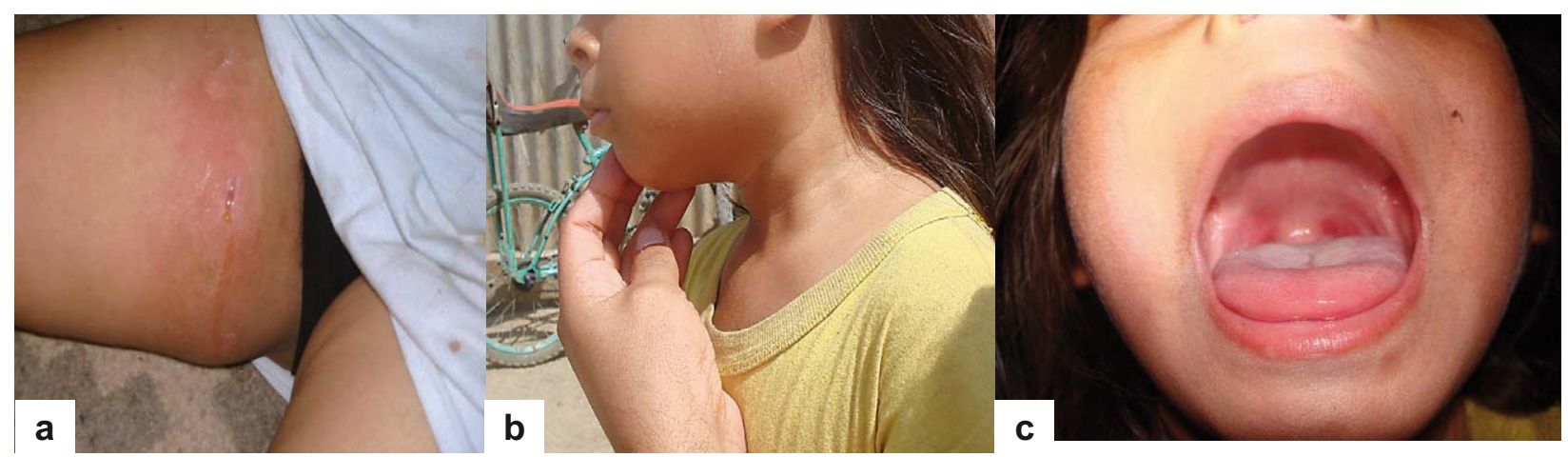

Figura 3. En el estudio de brote, se ha identificado diversas presentaciones clínicas de la peste en humanos: la forma bubónica clásica en zonas inguinales o cervicales, las formas faríngea, la forma septicémica y la forma neumónica. Formas clínicas de la peste bubónica: (a) bubón crural; (b) bubón cervical y (c) la forma faríngea. 


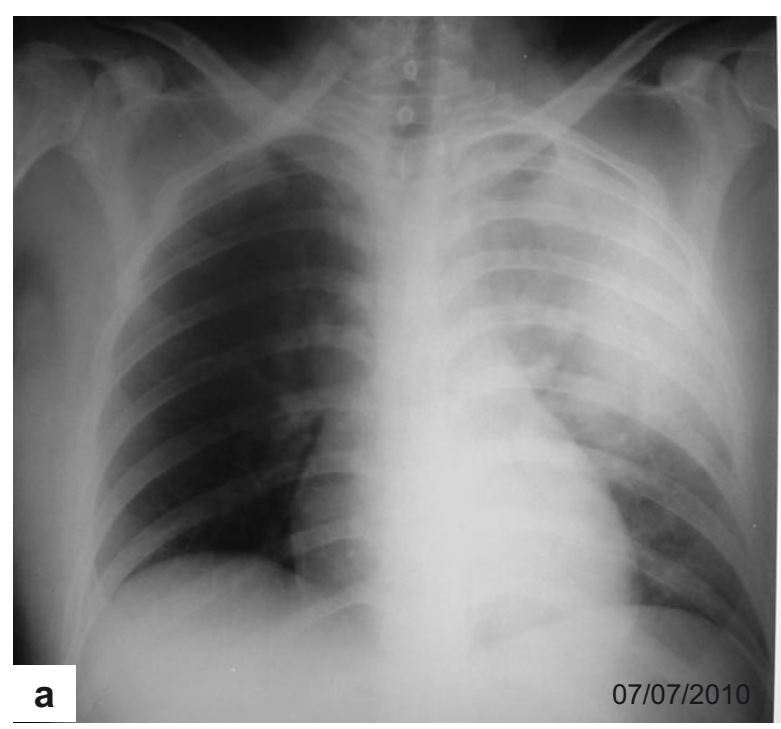

Figura 4. Radiografías de un caso de peste neumónica primaria después.

el costo para el departamento de Cajamarca fue de US \$ 2333169 dólares y para el año 1999 fue de US \$741 431 dólares. En la base de datos Medline solo hay dos publicaciones, una sobre un brote de peste en Huancabamba, Piura, con cinco casos en humanos ${ }^{(9)}$ y otra sobre la necesidad de un enfoque multisectorial para el control de peste en el Perú ${ }^{(10)}$.

\section{INVESTIGACIÓN EN EL INSTITUTO NACIONAL DE SALUD}

El Instituto Nacional de Salud viene realizando investigaciones colaborativas con la Gerencia Regional

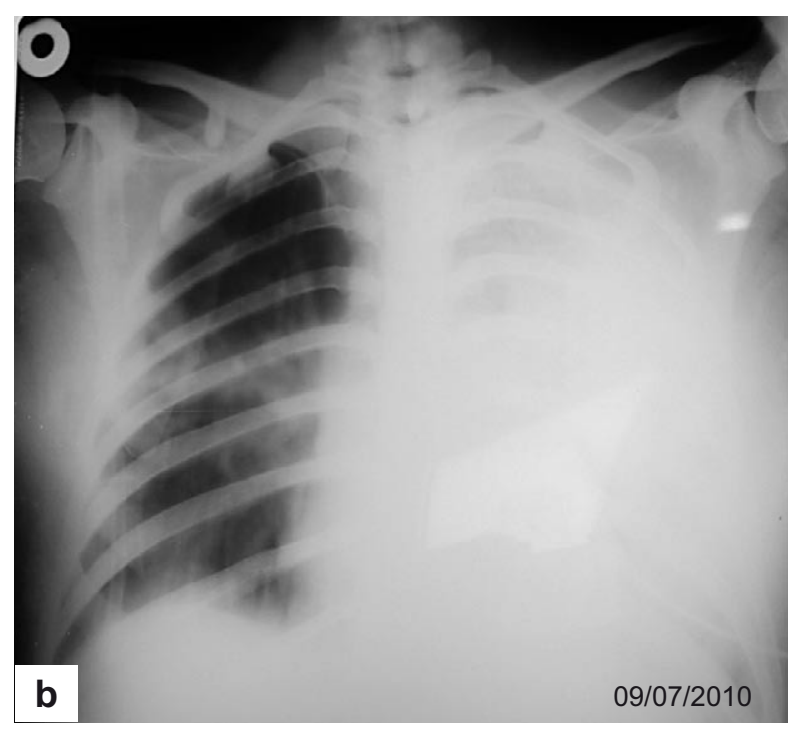

(a) Radiografía el día del ingreso, (b) la misma paciente dos días

de Salud (GERESA) de La Libertad desde mayo de 2010. En el contexto del brote, se decidió que la primera necesidad era conocer la dinámica de transmisión en el área afectada, básicamente el tipo de vectores, reservorios y las características de la afección en los pobladores del área con la finalidad de generar información para la toma de decisiones. Es por esto que se decidió realizar estudios en humanos, para determinar la prevalencia de anticuerpos específicos contra Y. pestis, las vías de transmisión y factores de riesgo para infectarse y enfermar. Asimismo, se llevó a cabo estudios para identificar los potenciales reservorios de $Y$. pestis y la dinámica de la población en el intradomicilio, peridomicilio y área silvestre, también

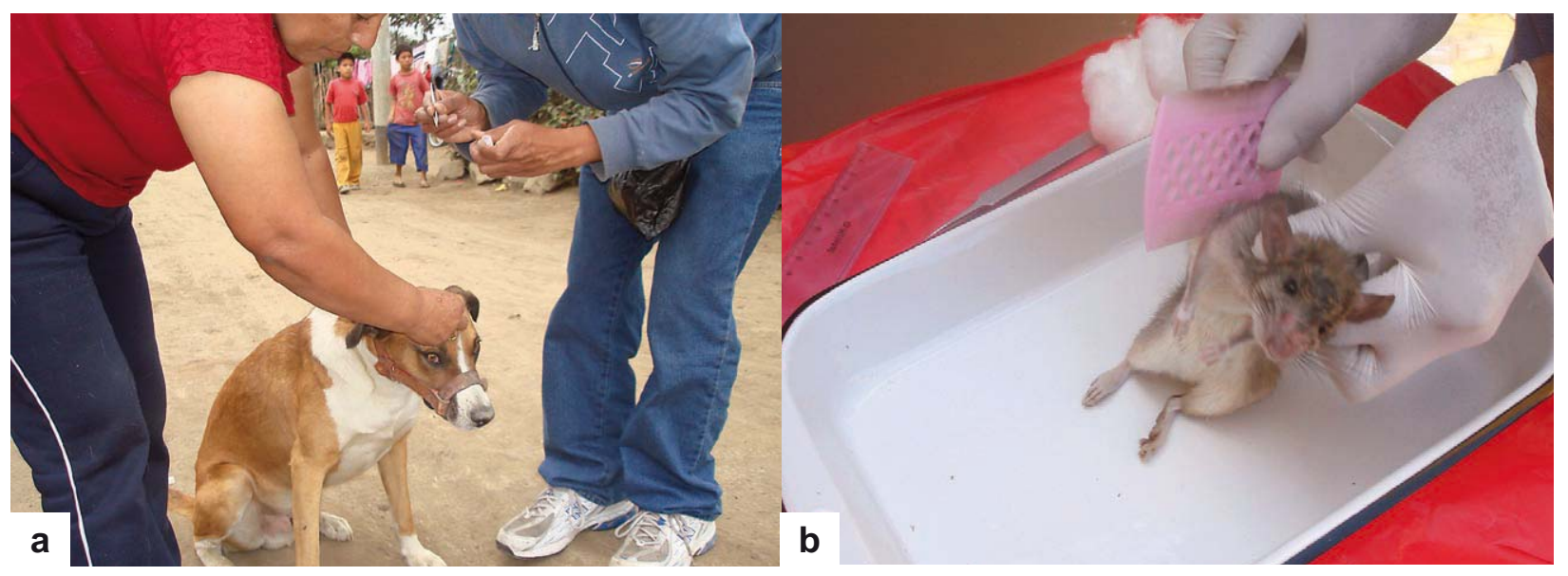

Figura 5. Estudio de vectores para identificar especies de pulgas vectores de Y. pestis. Colecta de pulgas en las áreas en riesgo. (a) en animales domésticos: perro y (b) en roedores capturados. También se ha realizado capturas de pulgas directas sobre frazadas, ropa de pobladores y animales domésticos; se ha capturado pulgas de las especies Pulex irritans, Pulex simulans, C. felis, C. canis y Echidnophaga gallinácea. Sobre los roedores se ha capturado Xenopsylla cheopis, E. gallinácea, C. felis y algunos ejemplares de Polygenis litargus. 


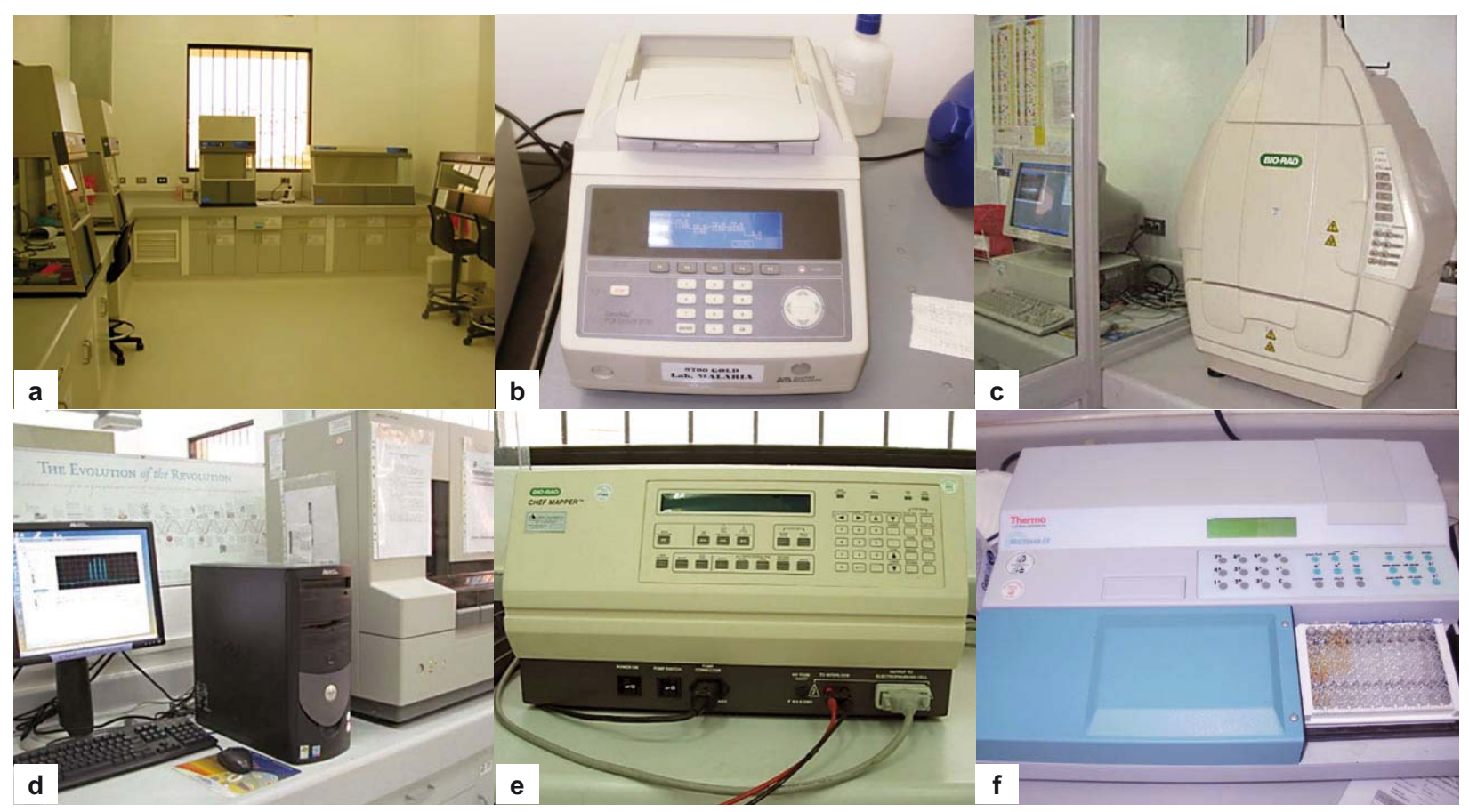

Figura 6. Equipos de laboratorio de biomedicina utilizados para estudios serológicos y de biología molecular en muestras de humanos, animales y vectores. (a) Área limpia para extracción de material genético; (b) termociclador; (c) documentador de geles; (d) secuenciador genético; (e) equipo para electroforesis de campo pulsado; (f) lector de ELISA.

estudios en vectores para determinar la susceptibilidad a los diferentes insecticidas e identificar las especies de pulgas responsables de la transmisión. Las técnicas que se están aplicando para la identificación del agente incluyen novedosas tecnologías de diagnóstico serológico, pruebas rápidas y de biología molecular, además, de pruebas convencionales para el aislamiento e identificación de Y. pestis. Como se puede apreciar, es amplio el espectro de actividades que el Instituto Nacional de Salud, en coordinación con la GERESA La Libertad, ha realizado en el contexto de este brote. Cada una de las áreas de estudio mencionadas constituye un proyecto de investigación; sin embargo, en la presente galería se presenta solamente una pequeña descripción de estas, con la finalidad de brindar al lector un panorama de la gama de intervenciones realizadas y cuyos resultados preliminares han contribuido a la toma de decisiones en la prevención y control del brote de peste en La Libertad, por parte de funcionarios del nivel local, regional y nacional.

\section{AGRADECIMIENTOS}

Agradecemos a los médicos Víctor Peralta, Pedro Díaz y Arístides Aurora por las facilidades logísticas

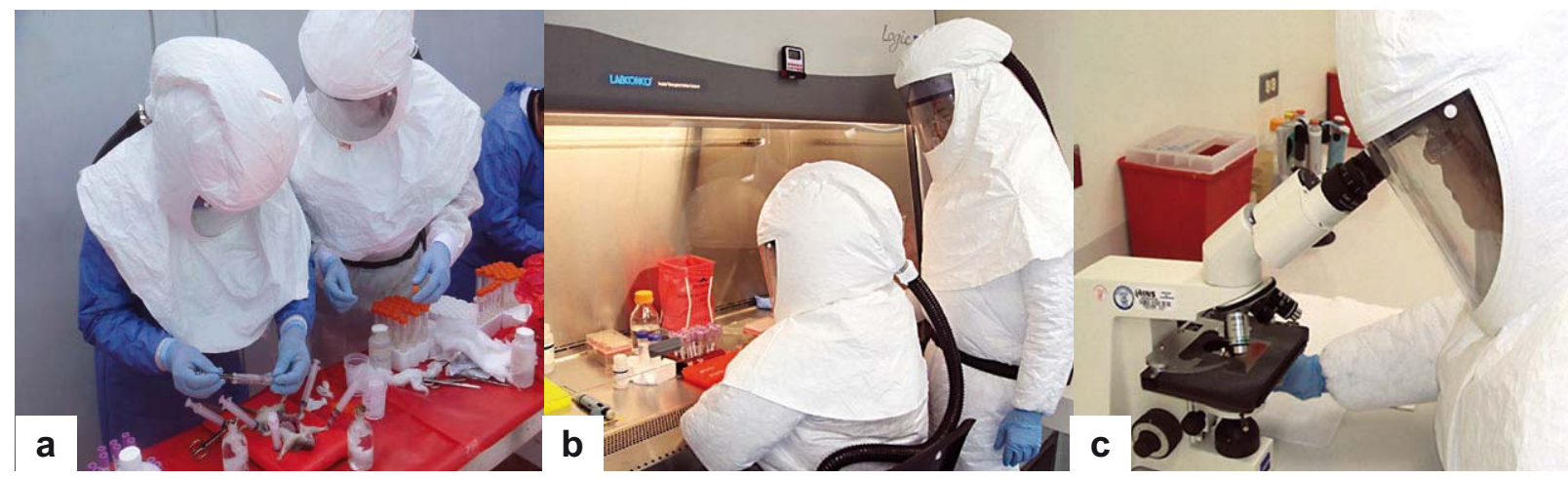

Figura 7. Bioseguridad en el trabajo de campo y los laboratorios del Instituto Nacional de Salud. (a) Equipo de bioseguridad PAPR (Powered Air Purifying Respirator) utilizado por el personal del INS en el trabajo de campo para colectar muestras de órganos de animales; (b) y (c) Nivel de bioseguridad III para realizar los cultivos de Yersinia pestis y observar las coloraciones de las muestras. 
brindadas para realizar los estudios de campo. También a los médicos César Cabezas, Pedro Valencia y Víctor Suárez del Instituto Nacional de Salud, por las facilidades brindadas al equipo en las investigaciones de campo y en el laboratorio de Biomedicina. A la Blga. Guisely Hijar por las fotos de equipos de Biomedicina y finalmente al equipo de médicos de la Unidad de Cuidados Intensivos del Hospital Regional Docente de Trujillo.

\section{Fuente de Financiamiento}

Instituto Nacional de Salud.

\section{Conflictos de Interés}

Los autores declaran no tener conflicto de interés en la publicación de este artículo.

\section{REFERENCIAS BIBLIOGRÁFICAS}

1. Stenseth NC, Atshabar BB, Begon M, Belmain SR, Bertherat E, Carniel E, et al. Plague: past, present, and future. PLoS Med. 2008;5(1):e3.

2. Perry RD, Fetherston JD. Yersinia pestis: etiologic agent of plague. Clin Microbiol Rev. 1997;10(1):35-66.

3. [No author listed]. Human plague in 2002 and 2003. Wkly Epidemiol Rec. 2002;79(33): 301-8.

4. World Health Organization. Interregional meeting on prevention and control of plague. Antananaviro, Madagascar, 7-11 April 2006. Geneva: WHO; 2008.

5. Arrieta M, Soto R, Gonzáles R, Nombera J, Holguín C, Monje J. Características de la población de roedores y pulgas en áreas de diferente riesgo para peste de tres provincias del departamento de Piura-Perú. Rev Peru Med Exp Salud Publica. 2001;18(3-4):90-97.
6. Pozo EJ, Troncos G, Palacios A, Arévalo F, Carrión G, Laguna-Torres VA. Distribución y hospederos de pulgas (Siphonaptera) en la provincia de Ayabaca, Piura - 1999. Rev Peru Med Exp Salud Publica. 2005;22(4):316-20.

7. Seraylán S, Vargas L. Purificación y control de calidad de la fracción antigénica F1 de Yersinia pestis. Rev Med Exp Salud Publica. 1999;14(1-2):48-50

8. Modesto J, Morales A, Cabanillas O, Díaz C. Impacto económico de la peste bubónica en Cajamarca - Perú. Rev Peru Med Exp Salud Publica. 2002;19(2):74-82.

9. Dávalos VA, Torres MA, Mauricci CO, Laguna-Torres VA, Chinarro MP. Outbreak of bubonic plague in Jacocha, Huancabamba, Perú. Rev Soc Bras Med Trop. 2001;34:87-90.

10. RuizA, NavarroAM, Vargas E, Sánchez J, SatoA, Escobar E. Peste bubónica en el Perú: un enfoque multisectorial de control. Bol Oficina Sanit Panam. 1996;121(4):363-67.

11. Donaires LF, Céspedes M, Valencia P, Salas JC, Luna ME, Castañeda $A$, et al. Peste neumónica primaria con transmisión intrahospitalaria en La Libertad, Perú 2010. Rev Peru Med Exp Salud Publica. 2010;27(3):367-72.

Correspondencia: Paul E. Pachas

Dirección: Capac Yupanqui 1400, Lima11, Perú.

Teléfono: (511) 650-9047

Correo electrónico: ppachas@ins.gob.pe

\section{Consulte las ediciones anteriores de la Revista Peruana de Medicina Experimental y Salud Pública en www.scielo.org.pe}

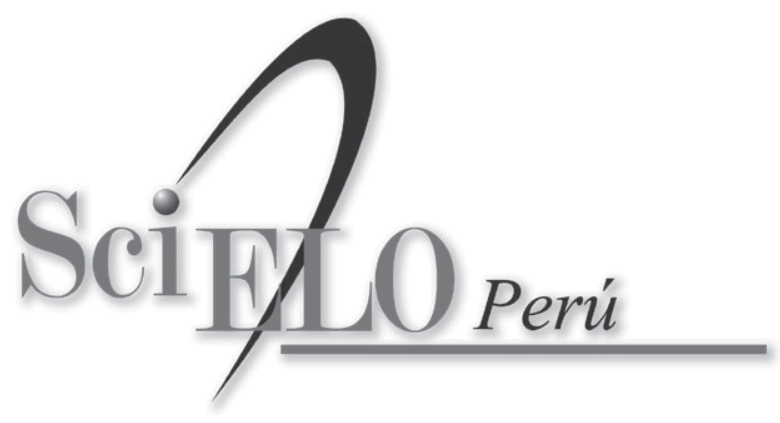

